\title{
Ultra-wideband Cork Substrate-Integrated-Waveguide Cavity-Backed Slot Antenna
}

\author{
Olivier Caytan* Sam Agneessens* \\ Piet Demeester ${ }^{\dagger}$
}

\begin{abstract}
An ultra-wideband (UWB) substrateintegrated-waveguide (SIW) cavity-backed slot antenna covering the lower part of the $3.1-10.6 \mathrm{GHz}$ block allocated to UWB transmission systems, being 3.1-3.6 GHz, is designed, constructed and validated. Owing to its planar topology, low profile and the use of cork substrate material, the proposed antenna may be integrated unobtrusively in any cork surface. Prior to the antenna design, the cork substrate material was characterized in the frequency band of interest. The design is conducted based on the average properties, while maintaining some impedance bandwidth margins to allow for varying cork material properties. A prototype is validated in freespace conditions, confirming the high performance observed in simulation. An impedance bandwidth of $700 \mathrm{MHz}(20.9 \%)$ is measured. At the center frequency $3.35 \mathrm{GHz}$, a radiation efficiency of $78 \%$, a

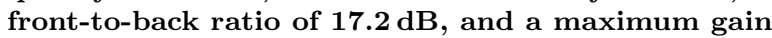
of $4.9 \mathrm{dBi}$ are obtained. The maximum gain varies only by $1.4 \mathrm{~dB}$ within the frequency band of interest. The other far-field properties also vary only negligibly, which is the most important requirement to UWB antennas.
\end{abstract}

\section{INTRODUCTION}

Radio-frequency identification (RFID) systems based on ultra-wideband (UWB) technology, and more in particular impulse radio UWB technology (IR-UWB), offer many advantages over RFID technologies operating in the ultra-high frequency (UHF) band. These benefits include a better range resolution, more robustness to interference and multipath, and higher security. Furthermore, the transmitter can operate at baseband, allowing a low power implementation [1]. UWB signals are defined by the Federal Communications Commission (FCC) as signals with an instantaneous spectral occupancy of $500 \mathrm{MHz}$ or more, or a fractional bandwidth of $20 \%$ or more. The FCC puts the frequency spectrum ranging from $3.1 \mathrm{GHz}$ to $10.6 \mathrm{GHz}$ at the disposal of UWB transmission systems [1].

Substrate-integrated-waveguide (SIW) cavity-

*Electromagnetics Group, Department of Information Technology, Ghent University/iMinds, 9000 Ghent, Belgium.

${ }^{\dagger}$ Internet Based Communication Networks and Services, Department of Information Technology, Ghent University/iMinds, 9000 Ghent, Belgium.

\author{
Sam Lemey* Dries Vande Ginste* \\ Hendrik Rogier*
}

backed antenna topologies [2] [3] exhibit many desirable properties for UWB applications. They provide high radiation efficiency, good front-to-back ratio (FTBR), and high isolation from their surroundings, making them suitable for low power applications. Various bandwidth enhancement techniques [3] can be applied to achieve an ultra-wide bandwidth. Finally, their low-profile allows for integration into floor and wall materials.

In this paper, an UWB SIW cavity-backed slot antenna covering the frequency range $3.1-3.6 \mathrm{GHz}$, being the lower part of the $3.1-10.6 \mathrm{GHz}$ FCC band for UWB transmission systems, is designed, constructed and validated. In [4], the same topology was adopted to realize a compact wearable RFID antenna made of textile materials, while here, the antenna is implemented on a cork substrate. Owing to the planar topology and low profile, the proposed antenna may be integrated unobtrusively in any cork surface. In [5], cork substrate material was used for narrow-band RFID applications, intended for use in bottle stoppers. Cork substrate material was also used in [6], with another antenna topology, to realize a compact wideband antenna for the $5 \mathrm{GHz}$ Wi-Fi band.

Section 2 discusses the characterization of the cork substrate and the design requirements, while Section 3 outlines the topology and the computeraided design of the SIW cavity-backed slot antenna. Measurements performed on a prototype in freespace conditions are presented in Section 4.

\section{CORK SUBSTRATE CHARACTERI- ZATION}

A composite cork agglomerate by Amorim Cork Composites S.A., made of cork granules bound by polyurethane, with a density of $0.145 \mathrm{~g} / \mathrm{cm}^{3}$ and a thickness of $3 \mathrm{~mm}$, is applied as antenna substrate.

Prior to the antenna design, the electrical parameters of the substrate material were determined in the frequency band of interest by the matrix-pencil two-line method in [7]. The measured dielectric constant $\epsilon_{r}$ and loss tangent $\tan \delta$, shown in Fig. 1a and Fig. 1b, are nearly constant in the [3-4 GHz] 


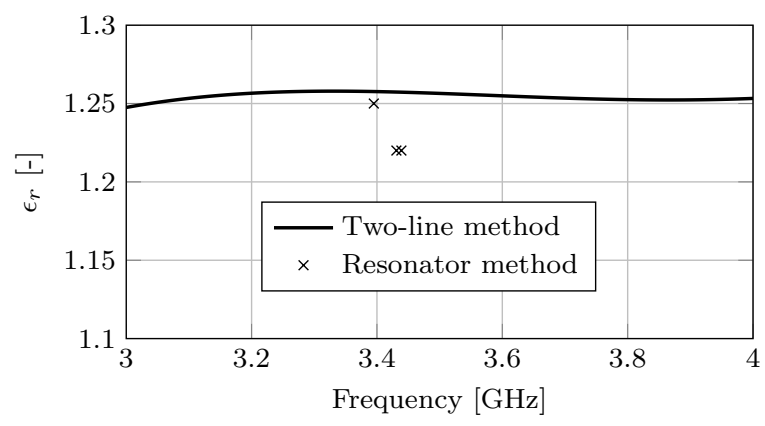

(a)

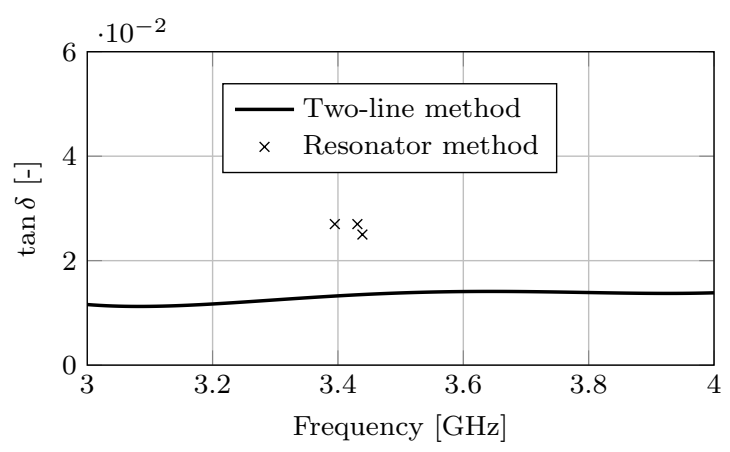

(b)

Figure 1: Measured electrical parameters of cork: dielectric constant $\epsilon_{r}$ (a) and loss tangent $\tan \delta(\mathrm{b})$.

range, and approximately equal to 1.25 and 0.013 , respectively.

To increase accuracy, the cork material was also characterized around $3.40 \mathrm{GHz}$ using the resonator technique described in [8]. Three resonators were constructed and characterized, yielding for $\left(\epsilon_{r}, \tan \delta\right)$ : $(1.25,0.027),(1.22,0.027)$ and $(1.22,0.025)$. These measurements are also shown in Figs. 1a and 1b.

The slight fluctuation in the different characterization results is due to inhomogeneity of the cork, caused by its cellular structure and porosity. The design is performed using the average parameters $\left(\epsilon_{r}=1.23\right.$ and $\left.\tan \delta=0.0263\right)$, while maintaining some impedance bandwidth margins to allow for varying cork material properties. A $-10 \mathrm{~dB}$ impedance bandwidth (w.r.t. $50 \Omega$ ) ranging from $3.05 \mathrm{GHz}$ to $3.65 \mathrm{GHz}$ is set as a requirement, providing coverage of the lower part of the 3.1-10.6 GHz FCC band for UWB transmission systems $(3.1-3.6 \mathrm{GHz})$ with $50 \mathrm{MHz}$ margins.

\section{ANTENNA TOPOLOGY AND DE- SIGN}

The wideband SIW cavity-backed slot antenna topology depicted in Fig. 2 is adopted, making use of the bandwidth enhancement method [9]. Both

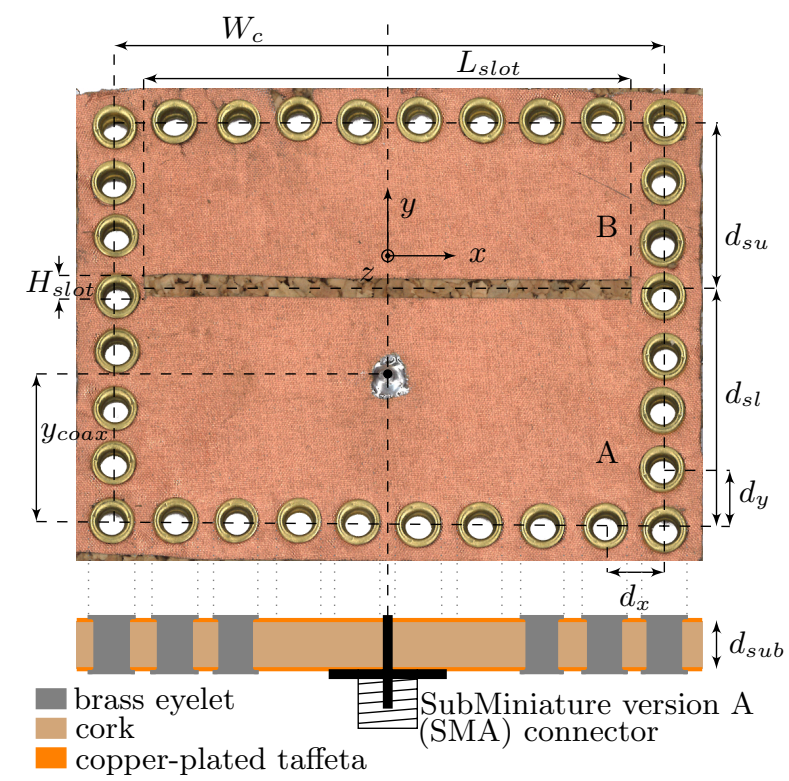

Figure 2: Substrate-integrated-waveguide (SIW) cavity-backed slot antenna topology. Optimized dimensions: $d_{\text {sub }}=3.0 \mathrm{~mm}, W_{c}=70.0 \mathrm{~mm}$, $d_{s u}=22.1 \mathrm{~mm}, d_{s l}=30.8 \mathrm{~mm}, H_{\text {slot }}=2.5 \mathrm{~mm}$, $L_{\text {slot }}=62.0 \mathrm{~mm}, y_{\text {coax }}=18.0 \mathrm{~mm}, d_{x}=7.8 \mathrm{~mm}$ and $d_{y}=7.6 \mathrm{~mm}$.

the top conducting antenna patch and the vias, forming the SIW cavity by connecting top patch and groundplane, are shown. The vias are realized by brass eyelets (outer diameter $d=4 \mathrm{~mm}$ ), spaced closely enough to minimize radiation loss $\left(d_{x} / d \leq 2\right.$ and $\left.d_{y} / d \leq 2\right)[2]$. A copper-plated taffeta electrotextile with a sheet resistance of $0.2 \Omega / \mathrm{sq}$ is applied for the conducting top patch and bottom groundplane. These electrotextile patches are attached to the cork substrate using thermally activated adhesive sheets.

The SIW cavity is split into half-cavities A and B by a non-resonant slot in the top patch, much longer than half a wavelength, leading to the simultaneous excitation of two hybrid cavity modes [9]. Correct dimensioning of the half-cavities and slot yields resonance frequencies of the two excited hybrid modes that are close together in the frequency band of interest, which leads to an enlarged impedance bandwidth. The lower resonance frequency hybrid mode consists of a weak $\mathrm{TE}_{110}$ and a strong $\mathrm{TE}_{120}$ resonance. The fields in halfcavities $\mathrm{A}$ and $\mathrm{B}$ are out of phase and the dominant fields are in half-cavity A. The higher resonance frequency hybrid mode consists of a weak $\mathrm{TE}_{120}$ with a strong $\mathrm{TE}_{110}$ resonance. The fields in half-cavities $\mathrm{A}$ and $\mathrm{B}$ are in phase and the dominant fields are in half-cavity B. The field distributions of both hybrid 
modes lead to consistent radiation by the slot. This enables wideband far-field properties, which is a key requirement for UWB antennas. The resulting antenna is linearly polarized and the YZ-plane is referred to as the E-plane, and the XZ-plane as the $\mathrm{H}$-plane. The structure is fed with a coaxial probe, positioned to magnetically couple efficiently to the two hybrid modes and to achieve good impedance matching.

The cavity width $W_{c}$ is fixed to $70.0 \mathrm{~mm}$, which allows for sufficient impedance bandwidth to meet the specifications. The length of the non-resonant slot $L_{\text {slot }}$ is chosen $62.0 \mathrm{~mm}$, much longer than half a wavelength. The other parameters, being halfcavity lengths $\left(d_{s l}\right.$ and $\left.d_{s u}\right)$, coaxial feed position $\left(y_{\operatorname{coax}}\right)$ and slot width $\left(H_{\text {slot }}\right)$, are optimized using the frequency solver of CST Microwave Studio to meet the specified impedance bandwidth. The values of the optimized antenna dimensions are added to the caption of Fig. 2. The corresponding simulated reflection coefficient is shown in Fig. 3. The two hybrid modes resonate at $3.21 \mathrm{GHz}$ and $3.55 \mathrm{GHz}$. Simulation of the far-field properties indicates that the broadside gain varies no more than $2.0 \mathrm{~dB}$ within the frequency band of interest.

\section{MEASUREMENTS}

A prototype has been constructed and characterized inside an anechoic chamber, to reproduce freespace conditions, using an Agilent N5242A PNA$\mathrm{X}$ Microwave Network Analyzer and an Orbit/FR DBDR antenna positioning system. Far-field gain patterns are measured with the gain comparison method using a standard gain horn model MI-122.6 .

Fig. 3 compares the simulated and measured input reflection coefficients. A good agreement is observed. The prototype exhibits an impedance bandwidth of $700 \mathrm{MHz}(20.9 \%)$, which is slightly higher than simulated. This is primarily a consequence of fabrication inaccuracies, and to a lesser extent of variation of the dielectric properties of cork material. The frequency band of interest, being 3.1$3.6 \mathrm{GHz}$, is fully covered.

Fig. 4 shows the simulated and measured farfield gain patterns at the lower $(3.10 \mathrm{GHz})$, center $(3.35 \mathrm{GHz})$ and upper frequency $(3.60 \mathrm{GHz})$, both in the E-plane and H-plane. The most important performance measurements, derived from the radiation patterns, are summarized in Table 1. These include the radiation efficiency $\eta_{\text {rad }}$, FTBR (defined as the ratio of the gain in the $+z$ direction to the gain in the $-z$ direction), maximum gain $G_{\max }$ and half-power beam width (HPBW) in the E-plane and H-plane. Again, a good agreement between mea-

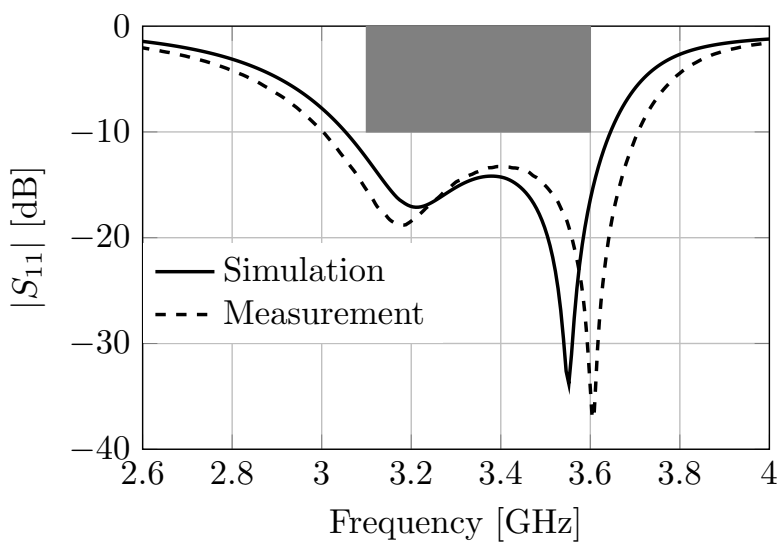

Figure 3: Simulated and measured input reflection coefficient $\left|S_{11}\right|[\mathrm{dB}]$ versus frequency.

Table 1: Measured (simulated) antenna characteristics at the lower frequency $3.10 \mathrm{GHz}$, the center frequency $3.35 \mathrm{GHz}$ and the upper frequency $3.60 \mathrm{GHz}$.

\begin{tabular}{r|c|c|c} 
freq. $[\mathrm{GHz}]$ & 3.10 & 3.35 & 3.60 \\
\hline$\eta_{\text {rad }}[\%]$ & $71(74)$ & $78(76)$ & $56(47)$ \\
\hline FTBR $[\mathrm{dB}]$ & $14.8(14.0)$ & $17.2(14.9)$ & $16.6(15.2)$ \\
\hline$G_{\max }[\mathrm{dBi}]$ & $4.6(5.8)$ & $4.9(6.0)$ & $3.5(4.0)$ \\
\hline HPBW [deg.] & & & \\
E-plane & $95(98)$ & $95(94)$ & $90(90)$ \\
H-plane & $55(65)$ & $60(66)$ & $60(68)$
\end{tabular}

surement and simulation is observed. The measurements indicate that the maximum gain, gain pattern shape, E-plane and H-plane HPBW, and the other far-field properties only vary slightly over the considered frequency band, which is a key requirement to UWB antennas. The variation of the maximum gain is smaller than predicted by simulation.

\section{CONCLUSION}

An UWB SIW cavity-backed slot antenna covering the lower part of the $3.1-10.6 \mathrm{GHz}$ block allocated to UWB transmission systems (3.1-3.6 GHz) was designed, constructed and validated. Owing to the planar topology, low profile and the use of cork substrate material, the proposed antenna may be integrated unobtrusively in any cork surface. Prior to the antenna design, the cork substrate material was characterized. The design was conducted based on the average properties, while maintaining some impedance bandwidth margins to allow for varying cork material properties. Measurements performed 


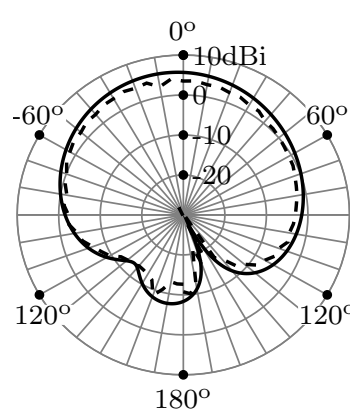

(a)

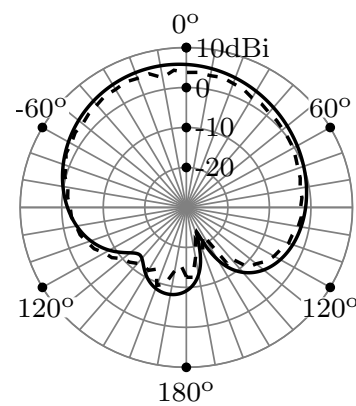

(c)

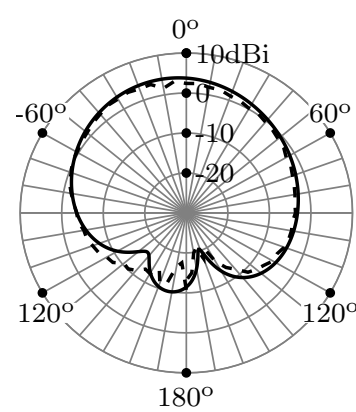

(e)

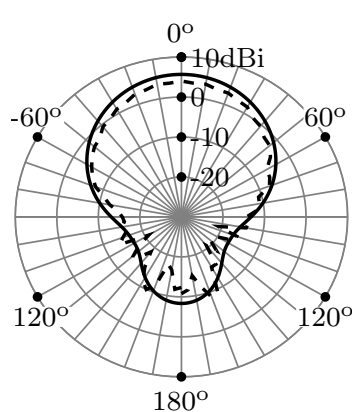

(b)

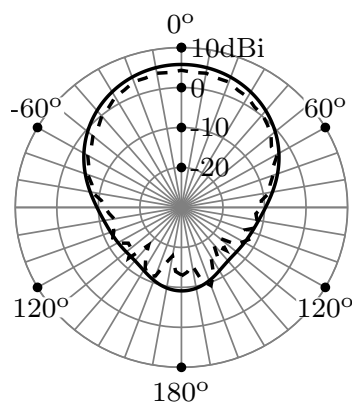

(d)

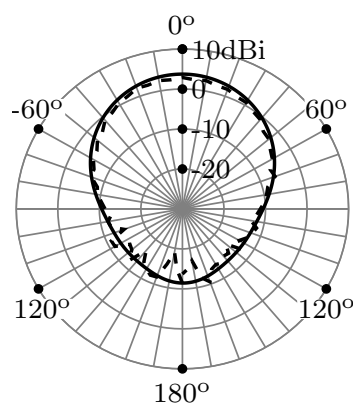

(f)
Figure 4: Far-field gain pattern [dBi] at the lower frequency $3.10 \mathrm{GHz}$ in (a) the E-plane and (b) the $\mathrm{H}$-plane, at the center frequency $3.35 \mathrm{GHz}$ in (c) the E-plane and (d) the H-plane, and at the upper frequency $3.60 \mathrm{GHz}$ in (e) the E-plane and (f) the $\mathrm{H}$-plane. Simulation (-) and measurement in freespace conditions $(---)$.

on a prototype in free-space conditions confirm the high performance observed in simulation and prove that the far-field properties only vary slightly over the considered frequency band, which is the most important requirement to UWB antennas.

\section{Acknowledgments}

Part of the work was supported by the iMinds IoT research program.

\section{References}

[1] D. Dardari, R. D'Errico, C. Roblin, A. Sibille, and M. Win, "Ultrawide Bandwidth RFID: The Next Generation?" Proceedings of the IEEE, vol. 98, no. 9, pp. 1570-1582, September 2010.

[2] M. Bozzi, A. Georgiadis, and K. Wu, "Review of substrate-integrated waveguide circuits and antennas," IET Microwaves, Antennas 83 Propagation, vol. 5, no. 8, pp. 909-920, June 2011.

[3] G. Q. Luo, T. Y. Wang, and X. H. Zhang, "Review of Low Profile Substrate Integrated Waveguide Cavity Backed Antennas," International Journal of Antennas and Propagation, vol. 2013, p. 7.

[4] S. Lemey and H. Rogier, "SIW textile antennas as a novel technology for UWB RFID tags," in 2014 IEEE RFID Technology and Applications Conference (RFID-TA), September 2014, pp. $256-260$.

[5] R. Goncalves, R. Magueta, P. Pinho, and N. Carvalho, "RFID passive tag antenna for cork bottle stopper," in 2014 IEEE Antennas and Propagation Society International Symposium (APSURSI), July 2014, pp. 1518-1519.

[6] O. Caytan, S. Lemey, S. Agneessens, D. Vande Ginste, P. Demeester, C. Loss, R. Salvado, and H. Rogier, "Half-mode substrate-integrated-waveguide cavity-backed slot antenna on cork substrate," IEEE Antennas and Wireless Propagation Letters, in press 2015.

[7] F. Declercq, H. Rogier, and C. Hertleer, "Permittivity and Loss Tangent Characterization for Garment Antennas Based on a New MatrixPencil Two-Line Method," IEEE Transactions on Antennas and Propagation, vol. 56, no. 8, pp. 2548-2554, August 2008.

[8] R. Moro, S. Agneessens, H. Rogier, A. Dierck, and M. Bozzi, "Textile Microwave Components in Substrate Integrated Waveguide Technology," IEEE Transactions on Microwave Theory and Techniques, vol. 63, no. 2, pp. 422-432, February 2015.

[9] G. Q. Luo, Z. F. Hu, W. J. Li, X. H. Zhang, L. L. Sun, and J. F. Zheng, "BandwidthEnhanced Low-Profile Cavity-Backed Slot Antenna by Using Hybrid SIW Cavity Modes," IEEE Transactions on Antennas and Propagation, vol. 60, no. 4, pp. 1698-1704, April 2012. 